\title{
Metallic small y stent placement at primary right carina for bronchial disease
}

\author{
Yonghua $\mathrm{Bi}^{1+}$, Jindong $\mathrm{Li}^{2 \dagger}$, Zepeng $\mathrm{Yu}^{1}$, Jianzhuang Ren ${ }^{1}$, Gang $\mathrm{Wu}^{1 *}$ and Xinwei Han ${ }^{1 *}$ (D)
}

\begin{abstract}
Background: Metallic large $Y$ stent placement has been used mainly for airway disease around the main carina. However, few studies have reported this treatment for bronchial disease around the primary right carina.
\end{abstract}

Methods: Twenty-eight patients were treated by small y stent. All stents were custom-designed and placed under fluoroscopic guidance. Clinical and imaging data were analyzed retrospectively.

Results: Thirty-one stents were successfully inserted in 28 patients. Twenty-five patients succeed at the first attempt (89.3\%), and 3 patients needed a second attempt. Twelve complications occurred in 10 patients (35. 7\%). Stent restenosis and sputum retention were the most common complications. Five patients underwent successful stent removal due to complications or cure efficacy. During follow up, 17 patients died of tumors and one died of myocardial infarction. The 1-, 3-, and 5-year survival rates were 49.3, 19.6 and 19.6\%, respectively.

Conclusions: Metallic small y stent placement is technically feasible, effective and safe for bronchial disease around the primary right carina.

Keywords: Bronchial fistula, Bronchial stenosis, Sten, Primary right carina, Fluoroscopy

\section{Background}

Metallic stent placement has been known as an effective treatment for patients with airway disease [110]. Metallic large $Y$ stent placement has been used mainly for airway disease around the main carina [11, 12]. Clinically, bronchial disease is also common shown around the primary right carina. For example, silicone small y stents have been used to treat airway disease around the left carina [13]. Placement of metallic small y stents can be less traumatizing with the help of guide wires [14], and may well be an alternative to the silicone y stent [14]. Unfortunately, few studies have reported the use of metallic small $y$ stents for the treatment of bronchial disease around primary right carina. In this study, we used the metallic y stent to treat bronchial disease that involved primary right carina, and aimed to determine the safety, feasibility and efficacy of this stenting technique.

\footnotetext{
* Correspondence: wuganghenan2004@126.com; dreamweaver08@126.com

${ }^{\dagger}$ Yonghua Bi and Jindong Li contributed equally to this work.

${ }^{1}$ Department of Interventional Radiology, the First Affiliated Hospital of

Zhengzhou University, Zhengzhou, China

Full list of author information is available at the end of the article
}

\section{Materials and methods \\ Patients}

From January 2011 to May 2017, 28 patients were treated for bronchial disease by metallic small y stent in our department. Bronchoscopy and chest spiral computed tomography (SCT) was used for the diagnosis of bronchial disease. The medical records of these patients were retrospectively reviewed. Bronchoscopy and chest SCT were used to confirm the diagnosis and determine the location of fistula or stenosis. Metallic airway stents were manufactured by Nanjing MicroTech Medical Company (Nanjing, China), and were woven with a nickel-titanium alloy wires (Fig. 1). The airway stents were designed according to the diameter and length of the bronchus (Fig. 2, a; Fig. 3, a, b). All the $\mathrm{Y}$ shape stent was custom manufactured by Micro-Tech Co. Ltd. (Nanjing, China). [12]

\section{Stenting procedure}

The stenting procedure was performed under fluoroscopic guidance [12]. A vertebral artery catheter (Cook Corporation, Bloomington, Ind, USA) was introduced 


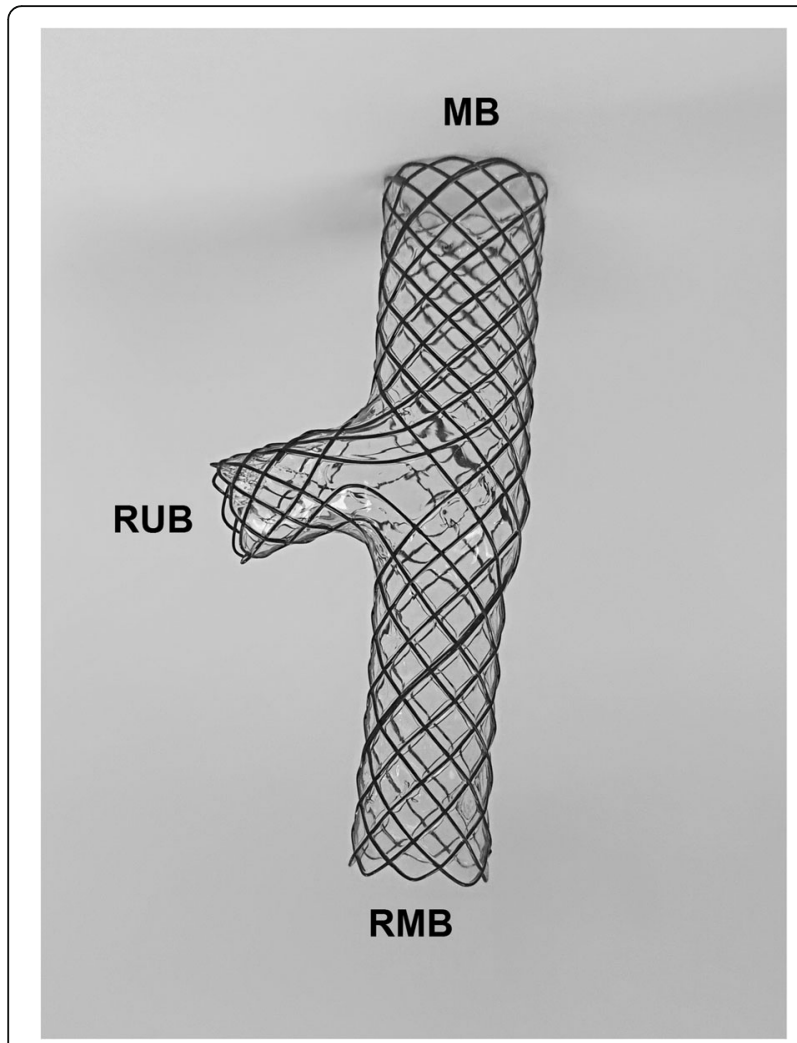

Fig. 1 Photo of metallic airway stent. MB: main body; RUB: right up bronchus; RMB: right middle bronchus

into the distal end of the right lobar bronchi. The location and size of the fistula or stenosis was confirmed by radiography. Then two stiff guide wires (Cook Corporation) were inserted into the distal end of the lobar bronchus. The small y stent was introduced into the primary right carina. The branches of the small y stent were deployed first, and the main body of the stent was deployed at the right main bronchus (Fig. 2, b). For stent removal, a long sheath and retrieval hook was inserted (Fig. 2, e; Fig. 4, c). The tip of the hook was placed next to the end of the stent and withdrawn from the airway wall (Fig. 2, f; Fig. 4, d). Radiography was performed again to show sealing of the fistula or patency of the stent immediately after stenting (Fig. 4, e).

\section{Follow up}

During follow up, bronchoscopy and chest SCT were used to show sealing of the bronchial fistula and stent patency, and radiography was performed if necessary (Fig. 2, c, d; Fig. 3, c, D; Fig. 4, f). Stent removal was conducted once a severe complication was found or patients were cured.

\section{Statistical analysis}

Data were expressed as mean \pm standard deviation, and analyzed by ANOVA. Qualitative data were expressed in percentage. Survival rate was compared by Log-rank (Mantel-Cox) Test (GraphPad Software, Inc., USA). Statistical significance was considered when $p<0.05$.

\section{Results}

\section{Patient characteristics}

Twenty-two patients were diagnosed with esophageal cancer; 4 patients, with lung cancer; and 2 patients, with tuberculosis or pulmonitis. Twenty-two patients underwent lobectomy due to lung cancer $(n=1)$ or resection of esophageal carcinoma $(n=21)$. After a median interval of 1.5 month, patients exhibited airway symptoms, with a median symptom duration of 1.0 month. Thoracogastric airway fistula $(71.4 \%)$ was the main indication for stent placement in this study. Other indications included airway stenosis and bronchopleural fistula (Table 1).

\section{Stenting procedure}

Stents were successfully inserted in 25 patients at the first attempt (89.3\%). Three patients underwent a successful second attempt, including 2 migrations during withdrawal of the guide wires and one partial obstruction of the left main bronchus due to stent retraction. A total of 31 small y stents were inserted. The median diameter of the stent is $14 \mathrm{~mm}$ for main body (Interquartile range, IQR 12, 16), $10 \mathrm{~mm}$ for the limb in the right upper bronchus (IQR 10, 12) and $10 \mathrm{~mm}$ for another limb in the right middle bronchus (IQR 8, 13). The median length of stent is $15 \mathrm{~mm}$ for the main body (IQR 10, 18), $12 \mathrm{~mm}$ for the limb in right upper bronchus (IQR 10,15) and $20 \mathrm{~mm}$ for another limb in the right middle bronchus (IQR 15, 25). Five patients underwent successful stent removal due to stent migration $(n=1)$, restenosis $(n=1)$ or cure efficacy $(n=3)$, with a median time of 76 days (IQR 25.5, 497.5). All of these stents were removed successfully at the first attempt with no complications.

\section{Complications}

No perioperative deaths or severe complications (massive hemorrhage or airway rupture) occurred during stent placement or removal. A total of 12 major complications occurred in 10 patients (35.7\%). Four patients showed stent restenosis after a median time of 65 days. Six patients showed sputum retention after a median time of 10.5 days, and endoscopic sputum aspiration was performed for these patients. Migration of two stents was found during withdrawal of the delivery system. One patient showed stent migration 11 days later due 

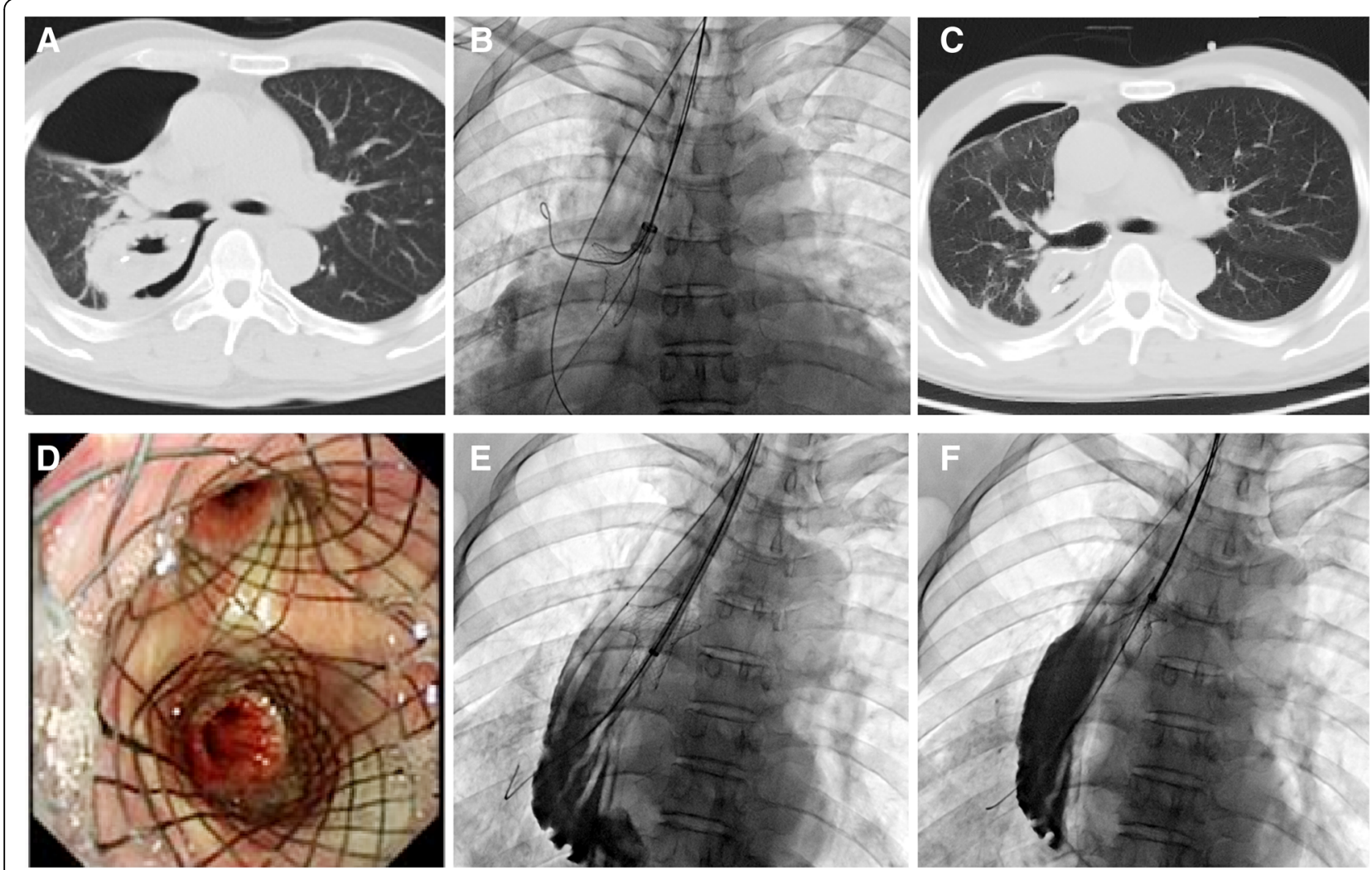

Fig. 2 Treatment of a 59-year-old man with fistula in right main bronchus. a, Chest SCT showed fistula in right main bronchus with right pneumothorax. b, Small y covered stent inserted in primary right carina. c, Chest SCT shows sealing of bronchial fistula with decreased right pneumothorax. $d$, Bronchoscopy confirmed complete seal of the fistula. E, A long sheath was introduced for stent removal after 167 days due to patient cure. F, Tip of hook was placed next to end of stent and stent was withdrawn from the airway wall


Fig. 3 Treatment of a 77-year-old woman with severe stenosis in right main bronchus. a, b, Chest SCT showed severe stenosis in right main bronchus and atelectasis. c, d After small y stent placement, chest SCT confirmed patency of right main bronchus and disappearance of atelectasis to frequent cough and a second small y stent was inserted after removal of the migrated one. All patients tolerated the stent well and had good palliation of airway symptoms (Table 2).

\section{Follow up}

Two patients were lost to follow up. The remaining 26 patients were followed up for a median time of 9.2 months (IQR 3.5-23.8 months). Seventeen patients died of tumors and one died of myocardial infarction during follow up. The 1-, 3-, and 5-year survival rates were $49.3,19.6$ and $19.6 \%$, respectively. The median survival was 12 months.

\section{Discussion}

Airway stents of various types and materials have been used for the treatment of airway disease, such as silicone stents [15-17] and metallic stents [1-9, $11,12]$. Small y stent placement may be applicable for patients with bronchial disease around the primary right carina. For example, the silicone y stent 

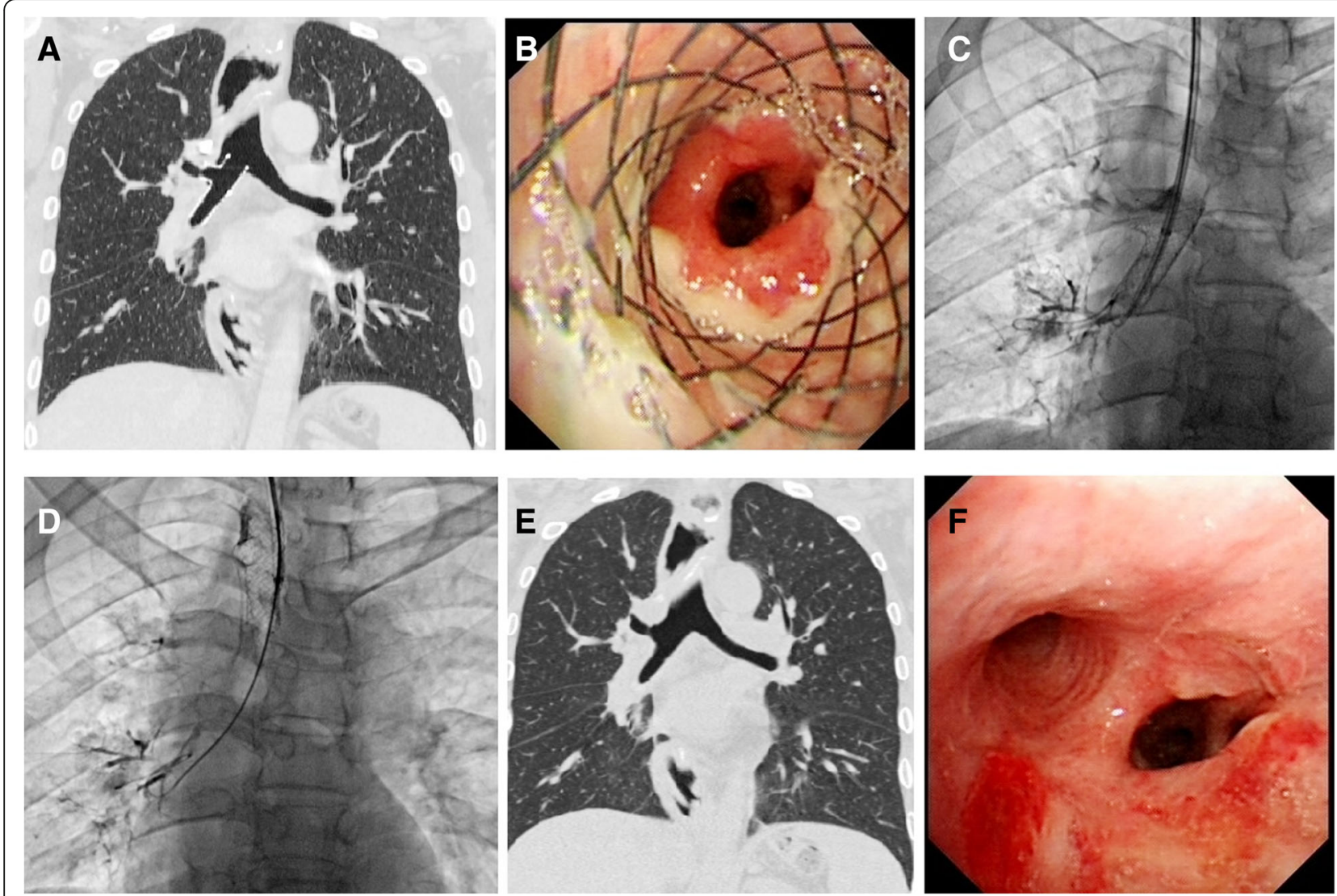

Fig. 4 7A 50-year-old man treated by stent placement and removal. a, Airway fistula in right middle lobe bronchus was treated by small y covered stent. b, Bronchoscopy shows sealing of bronchial disease with mild stent restenosis 40 days later. $c$, Tip of hook placed next to end of stent. $d$, Metal y stent was successfully withdrawn after 40 days. e, Chest SCT was performed again to confirm sealing of fistula immediately after stent removal. f, Bronchoscopy shows the patency of bronchus after stent removal

Table 1 The patients' characteristics

\begin{tabular}{ll}
\hline Characteristics & $\begin{array}{l}\text { Median (IQR) } \\
\text { or No. (\%) }\end{array}$ \\
\hline Patients, No. & 28 \\
Age, years & $59(51-64.5)$ \\
Male gender & $22(78.6 \%)$ \\
Duration of symptom, Months & $1.0(0.4-4.8)$ \\
Interval between surgery and & $1.5(0.5-13.8)$ \\
symptom, Months & \\
Duration of stenting procedure, Minutes & $31.5(19.5-44.3)$ \\
Previous disease & \\
Esophageal cancer & $22(78.6 \%)$ \\
Lung cancer & $4(14.3 \%)$ \\
Tuberculosis/pulmonitis & $2(7.1 \%)$ \\
Indications for stent placement & \\
Airway stenosis & $5(17.9 \%)$ \\
Thoracogastric airway fistula & $20(71.4 \%)$ \\
Bronchopleural fistula & $3(10.7 \%)$ \\
Location of fistula/stenosis & $6(21.4 \%)$ \\
Right bronchus & \\
Right middle lobe bronchus & \\
\hline
\end{tabular}

has been used for the treatment of airway disease around the left carina [13]. However, few studies have reported the use of metallic y stents for the treatment of bronchial disease around the primary right carina. Our study demonstrated that this technique is safe and feasible for these patients with good efficacy. In our study, stents were successfully inserted in all patients with no perioperative death or severe complications, such

Table 2 Clinic effect and complications of stenting

\begin{tabular}{lll}
\hline & $\mathrm{N}(\%)$ & Days after stenting \\
\hline Clinic efficacy & & \\
Cure or improved & $8(28.6 \%)$ & $31.8(25.6,34.4)$ \\
Death & $18(64.3 \%)$ & $9(3.9,53.4)$ \\
Loss of follow & $2(7.1 \%)$ & - \\
Complications & & \\
Stent restenosis & $4(14.3 \%)$ & $65(43.5,186.3)$ \\
Bronchus obstruction & $1(3.6 \%)$ & 0 \\
Stent migration & $3(10.7 \%)$ & $0(0,11)$ \\
Retention of sputum & $6(21.4 \%)$ & $1.5(5.3,169.3)$ \\
\hline
\end{tabular}


as massive hemorrhage or airway rupture. Twelve complications occurred in 10 patients. Stent restenosis and sputum retention were the most common complications, occurring in 4 and 6 patients, respectively. All of these complications were successfully treated by endoscopy or re-intervention.

Owing to easy removal, durability and low cost, the silicone stent is widely used clinically [13, 18-20]. However, metallic stents show good support and flexibility, can be placed with the help of guide wires, may be less traumatizing and minimize the procedures in cases with a fistula [14]. Currently, individualized metallic stents are available and can be produce upon request $[1,7$, 21]. Metallic large $Y$ stents were designed to be inserted for airway disease at the main carina. Owing to a low rate of stent migration, the metallic large $\mathrm{Y}$ stent placement on the primary carina may be an alternative to conventional straight stent placement. In this study, metallic small y stents were customized and used for airway disease around the primary right carina. According to our experience, metallic small y stent placement can be an alternative to silicone y stenting for airway disease around the primary right carina. In addition, implanted Y stents show excellent stability, with a low migration rate [22].

Oki et al. reported 3 cases of malignant disease treated with silicone y stent placement around the primary right carina [17]. The sample size of our study is significantly larger than that of his study, which helps to provide more reliable clinical experience. Metallic stent placement under fluoroscopic guidance dose not require the complex skills needed for rigid bronchoscopy, and this will contribute to the popularization and application of this technology. It needs to be pointed out that silicone stents have to be placed under rigid bronchoscopy only. In addition, rigid bronchoscopy is not only a way to access the airway but also a tool to achieve tumor debulking and dilation of stenosis.

The limitation of this study is its small retrospective nature. A larger prospective study is necessary to further investigate outcomes. In addition, good results of this study might not be reproduced at a less treatment experienced center. In conclusion, metallic small y stent placement is technically feasible, effective and safe for bronchial disease around primary right carina.

\section{Conclusions}

Metallic small y stent placement is technically feasible, effective and safe for bronchial disease around the primary right carina.

\section{Abbreviations}

IQR: interquartile range; SCT: spiral computed tomography
Acknowledgements

Not applicable.

\section{Funding}

This work was supported by National Natural Science Foundation of China (Grant No. 81501569). No funding body participated in the design of the study and collection, analysis, and interpretation of data and in writing the manuscript.

\section{Availability of data and materials}

The datasets used and/or analyzed during the current study are available from the corresponding author on reasonable request.

\section{Authors' contributions}

BYH, LDD, WG and HXW designed study. BYH, LJD, YZP performed study. YZP, RJZ collected and analyzed data. WG revised the manuscript. All authors wrote the paper and finally approved of the version to be published.

\section{Ethics approval and consent to participate}

This study obtained approval from the institutional review board of Zhengzhou University First Affiliated Hospital to review and publish information obtained from patient records. Written informed consent was obtained from all patients.

\section{Consent for publication}

We informed each patient of the publication, which includes the individuals personal data in any form (including individual details, images, or videos), and obtained written informed consent.

\section{Competing interests}

The authors declare that they have no competing interests.

\section{Publisher's Note}

Springer Nature remains neutral with regard to jurisdictional claims in published maps and institutional affiliations.

\section{Author details}

${ }^{1}$ Department of Interventional Radiology, the First Affiliated Hospital of Zhengzhou University, Zhengzhou, China. 'Department of Thoracic Surgery, the First Affiliated Hospital of Zhengzhou University, Zhengzhou, China.

Received: 20 July 2018 Accepted: 14 November 2018

Published online: 29 November 2018

References

1. Han X, Li L, Zhao Y, Liu C, Jiao D, Ren K, Wu G. Individualized airwaycovered stent implantation therapy for thoracogastric airway fistula after esophagectomy. Surg Endosc. 2017;31:1713-8.

2. Han X, Wu G, Li Y, Li M. A novel approach: treatment of bronchial stump fistula with a plugged, bullet-shaped, angled stent. Ann Thorac Surg. 2006; 81:1867-71.

3. Wu G, Li ZM, Han XW, Wang ZG, Lu HB, Zhu M, Ren KW. Right bronchopleural fistula treated with a novel, Y-shaped, single-plugged, covered, metallic airway stent. Acta Radiol. 2013;54:656-60.

4. Li TF, Duan XH, Han XW, Wu G, Ren JZ, Ren KW, Lu HB. Application of combined-type $Y$-shaped covered metallic stents for the treatment of gastrotracheal fistulas and gastrobronchial fistulas. J Thorac Cardiovasc Surg. 2016;152:557-63.

5. Stockton PA, Ledson MJ, Hind CR, Walshaw MJ. Bronchoscopic insertion of Gianturco stents for the palliation of malignant lung disease: 10 year experience. Lung Cancer. 2003;42:113-7.

6. Prasad M, Bent JP, Ward RF, April MM. Endoscopically placed nitinol stents for pediatric tracheal obstruction. Int J Pediatr Otorhinolaryngol. 2002;66: 155-60.

7. Han X, Al-Tariq Q, Zhao Y, Li L, Cheng Z, Wang H, Liu C, Jiao D, Wu G. Customized hinged covered metallic stents for the treatment of benign Main bronchial stenosis. Ann Thorac Surg. 2017;104:420-5.

8. Thornton RH, Gordon RL, Kerlan RK, LaBerge JM, Wilson MW, Wolanske KA Gotway MB, Hastings GS, Golden JA. Outcomes of tracheobronchial stent placement for benign disease. Radiology. 2006;240:273-82.

9. Park JH, Kim PH, Shin JH, Tsauo J, Kim MT, Cho YC, Kim JH, Song HY. Removal of retrievable self-expandable metallic tracheobronchial stents: an 
18-year experience in a single center. Cardiovasc Intervent Radiol. 2016;39: $1611-9$.

10. Ma J, Han X, Wu G, Jiao D, Ren K, Bi Y. Outcomes of temporary partially covered stent placement for benign tracheobronchial stenosis. Cardiovasc Intervent Radiol. 2016;39:1144-51.

11. Buskens $\mathrm{CJ}$, Hulscher JB, Fockens P, Obertop H, van Lanschot JJ. Benign tracheo-neo-esophageal fistulas after subtotal esophagectomy. Ann Thorac Surg. 2001;72:221-4.

12. Han XW, Wu G, Li YD, Zhang QX, Guan S, Ma N, Ma J. Overcoming the delivery limitation: results of an approach to implanting an integrated selfexpanding Y-shaped metallic stent in the carina. J Vasc Interv Radiol. 2008; 19:742-7.

13. Oki M, Saka H. New dedicated bifurcated silicone stent placement for stenosis around the primary right carina. Chest. 2013;144:450-5.

14. Oki M, Saka H. Silicone Y-stent placement on the secondary left Carina. Respiration. 2015;90:493-8.

15. Machuzak MS, Santacruz JF, Jaber W, Gildea TR. Malignant trachealmediastinal-parenchymal-pleural fistula after chemoradiation plus bevacizumab: management with a Y-silicone stent inside a metallic covered stent. J Bronchology Interv Pulmonol. 2015;22:85-9.

16. Murgu SD, Colt HG. Silicone $Y$ stent placement at secondary left carina for malignant central airway obstruction. J Thorac Cardiovasc Surg. 2010;139: 494-5.

17. Oki M, Saka H, Kitagawa C, Kogure Y. Silicone y-stent placement on the carina between bronchus to the right upper lobe and bronchus intermedius. Ann Thorac Surg. 2009:87:971-4.

18. Bolliger CT, Sutedja TG, Strausz J, Freitag L. Therapeutic bronchoscopy with immediate effect: laser, electrocautery, argon plasma coagulation and stents. Eur Respir J. 2006;27:1258-71.

19. Dahlqvist C, Ocak S, d'Odemont JP. New bifurcated silicone stent for the treatment of posttransplant bronchus intermedius stenosis: new silicone stent in posttransplant stenosis. Chest. 2014;145:429.

20. Lopez-Padilla D, Garcia-Lujan R, de Pablo A, de Miguel Poch E. Oki stenting for anastomotic bronchomalacia in lung transplantation. Eur J Cardiothorac Surg. 2015:48:e53-4.

21. Gompelmann D, Eberhardt R, Schuhmann M, Heussel CP, Herth FJ. Selfexpanding $Y$ stents in the treatment of central airway stenosis: a retrospective analysis. Ther Adv Respir Dis. 2013;7:255-63.

22. Dutau H, Toutblanc B, Lamb C, Seijo L. Use of the Dumon Y-stent in the management of malignant disease involving the carina: a retrospective review of 86 patients. Chest. 2004;126:951-8.

Ready to submit your research? Choose BMC and benefit from:

- fast, convenient online submission

- thorough peer review by experienced researchers in your field

- rapid publication on acceptance

- support for research data, including large and complex data types

- gold Open Access which fosters wider collaboration and increased citations

- maximum visibility for your research: over $100 \mathrm{M}$ website views per year

At $\mathrm{BMC}$, research is always in progress.

Learn more biomedcentral.com/submissions 